\title{
Corrigendum: A Brief Review of Paradigm Shifts in Prevention of Alzheimer's Disease: From Cognitive Reserve to Precision Medicine
}

\section{OPEN ACCESS}

Approved by:

Frontiers Editorial Office,

Frontiers Media SA, Switzerland

*Correspondence:

Chang Uk Lee

jihan@catholic.ac.kr

Specialty section:

This article was submitted to

Aging Psychiatry,

a section of the journal

Frontiers in Psychiatry

Received: 09 November 2019

Accepted: 13 November 2019

Published: 17 December 2019

Citation:

Hahn C and Lee CU (2019)

Corrigendum: A Brief Review of Paradigm Shifts in Prevention of Alzheimer's Disease: From Cognitive

Reserve to Precision Medicine.

Front. Psychiatry 10:900 doi: 10.3389/fpsyt.2019.00900

\section{Changtae Hahn ${ }^{1}$ and Chang Uk Lee ${ }^{2 *}$}

1 Department of Psychiatry, Deajeon Saint Mary's Hospital, College of Medicine, The Catholic University of Korea, Seoul, South Korea, ${ }^{2}$ Department of Psychiatry, Seoul Saint Mary's Hospital, College of Medicine, The Catholic University of Korea, Seoul, South Korea

Keywords: Alzheimer's disease, cognitive reserve, precision medicine, prevention, aging, biomarkers

\section{A Corrigendum on}

A Brief Review of Paradigm Shifts in Prevention of Alzheimer's Disease: From Cognitive Reserve to Precision Medicine

by Hahn C and Lee CU (2019). Front. Psychiatry. 10:786. doi: 10.3389/fpsyt.2019.00786

In the original article, there was an error regarding the corresponding author and the correspondence address provided. Instead of "Changtae Hahn, jihan@catholic.ac.kr" the correspondence should be addressed to "Chang Uk Lee, jihan@catholic.ac.kr".

The authors apologize for this error and state that this does not change the scientific conclusions of the article in any way. The original article has been updated.

Copyright () 2019 Hahn and Lee. This is an open-access article distributed under the terms of the Creative Commons Attribution License (CC BY). The use, distribution or reproduction in other forums is permitted, provided the original author(s) and the copyright owner(s) are credited and that the original publication in this journal is cited, in accordance with accepted academic practice. No use, distribution or reproduction is permitted which does not comply with these terms. 